\title{
Blood parasites infecting the Hoatzin (Opisthocomus hoazin), a unique neotropical folivorous bird
}

\author{
M. Andreína Pacheco ${ }^{\text {Corresp.., }}{ }^{1}$, M. Alexandra García-Amado ${ }^{2}$, Jaime Manzano ${ }^{3}$, Nubia E. Matta ${ }^{3}$, Ananias A \\ Escalante ${ }^{\text {Corresp. } 1}$ \\ ${ }^{1}$ Department of Biology/Institute for Genomics and Evolutionary Medicine (iGEM), Temple University, Philadelphia, PA, United States \\ 2 Laboratorio de Fisiología Gastrointestinal, Centro de Biofísica y Bioquímica, Instituto Venezolano de Investigaciones Científicas (IVIC), Caracas, Miranda, \\ Venezuela \\ 3 Departamento de Biología, Grupo de Investigación Caracterización genética e inmunología, Universidad Nacional de Colombia, Sede Bogotá-Facultad de \\ Ciencias, Bogota, Colombia
}

Corresponding Authors: M. Andreína Pacheco, Ananias A Escalante

Email address: tug00270@temple.edu, ananias.escalante@temple.edu

The Hoatzin (Opisthocomus hoazin) is the only extant member of the order Opisthocomiformes. This unique South American bird lives in the riparian lowland vegetation characteristic of the Amazon and Orinoco basins. Hoatzins nest in communal social units close to water bodies; they are strictly folivores being the only bird with pregastric fermentation in the crop. Because of the complex logistics involved in capturing this bird, there is a knowledge gap on its parasites. This study documents two distant lineages of haemosporidian parasites (Plasmodium spp.) in a juvenile and two adults sampled in the Cojedes state, Venezuela. Although negative by microscopy, the parasite identification was possible by using molecular methods. We estimated the phylogenetic relationships on the parasite cytochrome b (cytb, $480 \mathrm{bp}$ ) gene and the mitochondrial DNA. We found one of the parasites lineages in two individuals (nestling and adult), and the corresponding fragment of cytb was identical to a one found in Wood Stork (Mycteria americana) from Brazil. The other lineage, found in an adult, has an identity of 469 out of 478 bp (98\%) with Plasmodium sp. GAL-2012 (isolate THAMB08) from Brazil. Although a morphological description of these parasites was not possible, this is the first molecular study focusing on Hoatzin haemosporidian parasites and the first documentation of Plasmodium infections in the Hoatzin from Venezuela. Furthermore, we reported microfilaria in two adults as well as hematological parameters for six individuals. Information on hematological parameters could contribute to establishing the necessary baseline to detect underlying conditions, such as infections, in this bird species. 
1 Blood parasites infecting the Hoatzin (Opisthocomus hoazin), a unique neotropical

2 folivorous bird.

3

4 M. Andreína Pacheco ${ }^{1, *}$, M. Alexandra García-Amado ${ }^{2, \&}$, Jaime Manzano ${ }^{3, \&}$, Nubia E. Matta ${ }^{3}$, 5 Ananias A. Escalante ${ }^{1, *}$

6

7 Department of Biology/Institute for Genomics and Evolutionary Medicine (iGEM), Temple

8 University, Philadelphia, Pennsylvania, USA.

9 2Laboratorio de Fisiología Gastrointestinal, Centro de Biofísica y Bioquímica, Instituto

10 Venezolano de Investigaciones Científicas (IVIC), Miranda, Venezuela.

$11{ }^{3}$ Universidad Nacional de Colombia, Sede Bogotá-Facultad de Ciencias, Departamento de

12 Biología, Grupo de Investigación Caracterización genética e inmunología, Carrera 30 No. 45-03,

13 Bogotá 111321, Colombia.

$17 \&$ contributed equally

$18 *$ Corresponding author:

19 M. Andreina Pacheco ${ }^{1}$

20 Email address: Maria.Pacheco@temple.edu;

21 Ananias A. Escalante ${ }^{1}$

22 Email address: Ananias.Escalante@temple.edu 


\section{Abstract}

24 The Hoatzin (Opisthocomus hoazin) is the only extant member of the order Opisthocomiformes. This unique South American bird lives in the riparian lowland vegetation characteristic of the Amazon and Orinoco basins. Hoatzins nest in communal social units close to water bodies; they are strictly folivores being the only bird with pregastric fermentation in the crop. Because of the complex logistics involved in capturing this bird, there is a knowledge gap on its parasites. This study documents two distant lineages of haemosporidian parasites (Plasmodium spp.) in a juvenile and two adults sampled in the Cojedes state, Venezuela. Although negative by microscopy, the parasite identification was possible by using molecular methods. We estimated the phylogenetic relationships on the parasite cytochrome b (cytb, $480 \mathrm{bp})$ gene and the mitochondrial DNA. We found one of the parasites lineages in two individuals (nestling and adult), and the corresponding fragment of $c y t b$ was identical to a one found in Wood Stork (Mycteria americana) from Brazil. The other lineage, found in an adult, has an identity of 469 out of 478 bp (98\%) with Plasmodium sp. GAL-2012 (isolate THAMB08) from Brazil. Although a morphological description of these parasites was not possible, this is the first molecular study focusing on Hoatzin haemosporidian parasites and the first documentation of Plasmodium infections in the Hoatzin from Venezuela. Furthermore, we reported microfilaria in two adults as well as hematological parameters for six individuals. Information on hematological parameters could contribute to establishing the necessary baseline to detect underlying conditions, such as infections, in this bird species. 
46

47

48

\section{INTRODUCTION}

The Hoatzin (Opisthocomus hoazin), the only extant species of the Order Opisthocomiformes, is a unique bird native to the Orinoco and the Amazon basins in South America that includes Bolivia, Colombia, Ecuador, Peru, Venezuela, Brazil, and the lowlands of the Guianas. Little is known about its ecology and evolution. The lack of information is due in part to difficulties accessing its habitat, as well as the behavior and size of these birds that makes them hard to capture. In Venezuela, this species is distributed along rivers of the central savannas to the eastern Orinoco River. They live in colonies in riverine and swamp forest, vegetation at edges of ponds, oxbow lakes, and other freshwater wetlands. It is folivore bird that feeds on riverine tree species, and nests in communal social units building their nest close to water bodies (Thomas, 1996). Its phylogenetic relationship remains an enigma (Jarvis et al., 2014; Claramunt \& Cracraft, 2015; Prum et al., 2015). However, given that is the only bird with pregastric fermentation in the crop like that in ruminants (Grajal et al., 1989), most of the knowledge about this species is on the crop microorganism's community structure and ecology (e.g., Godoy-Vitorino et al., 2010, 2012; Bardele et al., 2017). Indeed, there are only a few studies on ectoparasites (Hernandes \& Mironov, 2015; Bauchan et al., 2017) and hemoparasite infections in the Hoatzin (Renjifo et al., 1952; Gabaldon, 1998). Only filarial parasite infections have been reported in the Hoatzin from Colombia (Renjifo et al., 1952), and no haemosporidian parasites had been found before in this species using blood films (Renjifo et al., 1952; Gabaldon, 1998).

In this study, we report two distant molecular lineages of haemosporidian parasites of the genus Plasmodium (Family Plasmodiidae, Order Haemosporida, Phylum Apicomplexa) found in the Hoatzin from the Cojedes River, a tributary of the Orinoco River in central Venezuela that is part of the Orinoquia. Plasmodiidae is a diverse group of vector-borne haemoparasites found in many 
terrestrial vertebrate hosts (Garnham, 1966; Valkiūnas, 2005; Telford, 2009), including the species of human (Cavalier-Smith, 2014) and avian malaria (e.g. Plasmodium relictum; Bensch et al. 2009; Atkinson \& Samuel, 2010). This is the first evidence of Plasmodium infections in the Hoatzin in South America; additionally, we provided hematological parameters to generate information that may help to assess the health status of this bird species.

\section{MATERIAL AND METHODS}

\section{Study area and samples}

We caught eight individuals in El Baúl massif along the Cojedes River near the town of El Baúl located at the southwestern of the Cojedes state in the northcentral Venezuela. This is considered part of the Orinoquia region at the north of the Guyana Shield. El Baúl massif is about $720 \mathrm{~km} 2$; it is relatively isolated and mountainous with steep topography following a northwest-southeast trend (Viscarret et al., 2009). The vegetation is typical of the Orinoquia sedimentary and alluvial plains (e.g., vegetation of savannas, gallery forests, palm groves, and semi-deciduous forests). In the context of this study, the birds were captured in the gallery forest, which is moderately intervened and subject to seasonal flooding from the Cojedes River as well as forest fires (González-Fernández et al., 2007).

We trapped two individuals (one adult and one juvenile) in October 2010, and 6 individuals (two adult and 4 nestlings) in August 2015 in their nest during nighttime using butterfly nets and transported to the field laboratory. From each bird, we obtained blood samples by brachial vein puncture, and then, immediately we prepared three to five thin smears. We preserved the rest of the sample in protein saver cards (Whatman 903, Whatman ${ }^{\mathrm{TM}}$, Cardiff, UK) for molecular analysis. We collected the specimens under permit number 0950 issued by the Venezuelan government 
92 (Oficina Nacional de Diveridad Biologica, Ministerio del Poder Popular para Ecosocialismo,

93 Hábitat y Vivienda). All the animal protocols were approved by the ethics committees of Instituto

94 Venezolano de Investigaciones Cientificas (IVIC, Venezuela) under the number COBIANIM ${ }^{\circ}$

95 Dir-0885/1517/2014.

96 Examination of blood films

97 Smears were air-dried immediately after preparation, fixed in absolute methanol for $5 \mathrm{~min}$, and 98 then stained with Giemsa ( $\mathrm{pH}$ 7.2) for 45 min. Using a Leica DM750e microscope (Leica 99 Microsystems, Heerbrugg, Switzerland), we first examined blood slides at x400 for 10 min and 100 then at x1000 for $20 \mathrm{~min}$. For the capture of digital images, we scanned entirety those slides with 101 hemoparasites using a Leica EC3 digital camera and processed with the LAS EZ (Leica 102 Microsystems Suiza Limited 2012). Then, we estimated the intensity of infection as No. of 103 parasites/ 10000 erythrocytes from erythrocyte counts with an increase of $x 1000$, focusing on areas 104 where blood cells formed a monolayer (Muñoz et al., 1999). In addition, using ImageJ software 105 (Schneider et al., 2012), we performed morphometric analyses of the erythrocytes. We measured 106 the maximum cell width and length, as well as nuclear width and length for 30 erythrocytes per 107 slide and per individual, following Hartman and Lessler (1963). To estimate the percentage of each 108 type of white blood cell present in blood, we also measured a differential white blood cell (WBC) 109 count per 100 cells using the blood samples collected in 2015 following the protocol by Clark 110 (2009). We obtained all these measures for only those individuals caught in $2015(N=6)$ because 111 of the better quality of their blood films.

\section{Molecular diagnostic of haemosporidian parasites}

113 We extracted genomic DNA from whole blood using QIAamp® DNA Micro Kit (Qiagen GmbH, 114 Hilden, Germany). We screened each sample for haemosporidian parasites by using a nested 
115 polymerase chain reaction (PCR) protocol that targets the parasite mitochondrial cytochrome $\mathrm{b}$

116 (cytb, 1,131 bp) gene using the primers described in Pacheco et al., (2011, 2018). The cytb external

117 primers were forward AE298 5'-TGT AAT GCC TAG ACG TAT TCC 3' and reverse AE299 5'-

118 GT CAA WCA AAC ATG AAT ATA GAC 3', and the internal primers were forward AE064 5'-

119 T CTA TTA ATT TAG YWA AAG CAC 3' and reverse AE066 5'-G CTT GGG AGC TGT AAT

120 CAT AAT 3'. The primary PCR amplifications were carried out in $50 \mu 1$ volume reaction using 5-

$1218 \mu \mathrm{l}$ of total genomic DNA, $2.5 \mathrm{mM} \mathrm{MgCl}_{2}$, 1X PCR buffer, $1.25 \mathrm{mM}$ of each deoxynucleoside

122 triphosphate, $0.4 \mathrm{mM}$ of each primer, and $0.03 \mathrm{U} / \mu 1$ AmpliTaq polymerase (Applied Biosystems,

123 Roche-USA). The primary PCR conditions were: A partial denaturation at $94{ }^{\circ} \mathrm{C}$ for 4 min and 36

124 cycles with $1 \mathrm{~min}$ at $94{ }^{\circ} \mathrm{C}, 1 \mathrm{~min}$ at $53{ }^{\circ} \mathrm{C}$ and 2 min extension at $72{ }^{\circ} \mathrm{C}$, and we added a final

125 extension of $10 \mathrm{~min}$ at $72{ }^{\circ} \mathrm{C}$ in the last cycle. Then, the nested PCRs were also made in $50 \mu 1$

126 volume reaction using only $1 \mu \mathrm{l}$ of the primary PCRs, $2.5 \mathrm{mM} \mathrm{MgCl} 2,1 \times$ PCR buffer, $1.25 \mathrm{mM}$

127 of each deoxynucleoside triphosphate, $0.4 \mathrm{mM}$ of each primer, and $0.03 \mathrm{U} / \mu \mathrm{l}$ AmpliTaq

128 polymerase. The nested PCR conditions were: A partial denaturation at $94{ }^{\circ} \mathrm{C}$ for 4 min and 25

129 cycles with $1 \mathrm{~min}$ at $94^{\circ} \mathrm{C}, 1 \mathrm{~min}$ at $56^{\circ} \mathrm{C}$ and $2 \mathrm{~min}$ extension at $72{ }^{\circ} \mathrm{C}$, and we also added a final

130 extension of $10 \mathrm{~min}$ at $72^{\circ} \mathrm{C}$ in the last cycle. Both strands for all the $c y t b$ fragments were directly

131 sequenced using an Applied Biosystems 3730 capillary sequencer. We identified all the $c y t b$

132 fragments obtained here as Plasmodium using BLAST (Altschul et al., 1997).

133 For those samples that were positive using the $c y t b$ PCR protocol, we amplified between 5515

134 to $5838 \mathrm{bp}$ of the parasite mitochondrial genomes (mtDNA) using a nested PCR with Takara LA

135 Taq ${ }^{\mathrm{TM}}$ Polymerase (TaKaRa Takara Mirus Bio) following manufacturers' directions. This

136 fragment of the mtDNA included the three nonprotein coding regions between the ORFs

137 (fragmented SSU rRNA and LSU rRNA) and the three protein-coding genes (Cox3, Cox1 and 
$138 C y t b)$ so only three tRNAs $(7,11$, and 14) and two fragments of small subunit ribosomal RNAs (5

139 and 7) are missing. Oligos forward AE170 5' GAGGATTCTCTCCACACTT

140 CAATTCGTACTTC $3^{\prime}$ and reverse AE171 5'

141 TAGACCGAACCTTGGACTC 3' were used for the primary PCR and internal oligos forward

142 AE176 5' TTTCATCCTTAAATCTCGTAAC $3^{\prime}$ and AE136 reverse 5' GACCGAA

143 CCTTGGACTCTT 3 ' for the inner PCR. The PCR conditions were a partial denaturation at $94{ }^{\circ} \mathrm{C}$

144 for $1 \mathrm{~min}$ and 30 cycles with $30 \mathrm{sec}$ at $94{ }^{\circ} \mathrm{C}$ and $7 \mathrm{~min}$ at $68^{\circ} \mathrm{C}$ and a final extension of $10 \mathrm{~min}$ at

$14572{ }^{\circ} \mathrm{C}$. Then, we excised two independent PCR products (50ul) from the gel (bands of 146 approximately 2 kbp) and purified using QIAquick ${ }^{\circledR}$ Gel extraction kit (Qiagen, GmbH, Hilden,

147 Germany). We cloned at least two independent PCR products using pGEM®-T Easy Vector

148 Systems (Promega, USA), and we sequenced four clones from each individual. We sequenced both 149 strands for PCR products and clones using an Applied Biosystems 3730 capillary sequencer. Given 150 that the $c y t b$ partial sequences and the $c y t b$ gene from the mtDNA genome were $100 \%$ identical 151 for each sample, we only deposited the mtDNA genome sequences in GenBank under the 152 accession numbers KY653749 to KY653751.

\section{Phylogenetic analysis of the cytb fragment and mtDNA genome}

154 We performed two different nucleotide alignments by using ClustalX v2.0.12 and Muscle as 155 implemented in SeaView v4.3.5 (Gouy et al., 2010) with manual editing. The first alignment was 156 constructed with $45 c y t b$ partial sequences (480 bp) belonging to three genera (Leucocytozoon, 157 Haemoproteus, and Plasmodium). This alignment included the sequences obtained in this study as 158 well as sequences from well-known parasite species based on morphology (Valkiūnas and Iezhova 159 2018) that were available in GenBank (Benson et al., 2012) and MalAvi (Bensch et al., 2009) 160 databases at the time of this study. Sequences that showed a similarity $>95 \%$ using BLAST 
161 (Altschul et al., 1997) were also included even when they are not clearly linked to the described

162 species. The second alignment (5286 bp excluding gaps) was done using $31 \mathrm{mtDNA}$ genome

163 sequences belonging also to the three genera, including the sequences obtained in this study and 164 sequences from well-known parasite species (using morphology) available in GenBank. 165 Subsequently, the alignment was divided into six partitions corresponding to the three non-protein 166 coding regions between the ORFs (fragmented SSU rRNA and LSU rRNA) and the three protein167 coding genes, keeping their order in the mtDNA genome (nonprotein coding, cox3, nonprotein 168 coding, coxl, cytb, nonprotein coding).

169 Then, we inferred phylogenetic hypotheses based on the first (partial cytb gene) and second 170 (mtDNA genome) alignments using the Bayesian methods implemented in MrBayes v3.2.6 with 171 the default priors (Ronquist \& Huelsenbeck, 2003). To estimate the phylogenetic hypothesis that 172 best fit the data, we used the general time reversible model with gamma-distributed substitution 173 rates and a proportion of invariant sites $(\mathrm{GTR}+\Gamma+\mathrm{I})$ on the $c y t b$ alignment and for each partition 174 in the mtDNA genome alignment. This model was the one with the lowest Bayesian Information 175 Criterion (BIC) scores for both alignments and each partition as estimated by MEGA v7.0.14 176 (Kumar et al., 2016). We inferred Bayesian support for the nodes in MrBayes by sampling every 1771000 generations from two independent chains lasting 4X10 ${ }^{6}$ Markov Chain Monte Carlo 178 (MCMC) steps. The chains were assumed to have converged once the value of the potential scale 179 reduction factor (PSRF) was between 1.00 and 1.02 and the average SD of the posterior probability 180 was $<0.01$ (Ronquist and Huelsenbeck 2003). Then, we discarded $25 \%$ of the sample once 181 convergence was reached as a "burn-in". For both phylogenies, we used Leucocytozoon species as 182 out-group. Genbank accession numbers for all sequences used in the analyses are given in the 183 phylogenetic trees. 


\section{RESULTS}

186

187

188

190

191

192

193

194

195

196

197

198

199

200

201

202

203

204

205

In this study, one sample was positive for haemosporidian parasites by microscopy (adult caught in 2015). The individual had only Plasmodium sp. trophozoites in its blood films (Fig. 1), so a morphological description of this parasite was not possible. Indeed, the parasitemia was very low $(<0.01)$, consistent with a subpatent infection. In addition, the two adults caught in 2015 were infected with microfilariae, so one of the adults has a coinfection of filarial parasites and Plasmodium sp. (Fig. 1). Unfortunately, the identification of nematode microfilariae at species level is difficult given their high degree of morphological and morphometric similarities (McKeand, 1998). None of the nestlings were infected with hemoparasites. Morphometry of the uninfected erythrocytes is shown in Table 1. We compared these measurements with those from the erythrocytes of other avian species with similar body size. In addition, we provided differential white blood cell (WBC) count profiles in Table 2.

The molecular diagnostic detected that the two individuals caught in 2010 (one adult and one juvenile) and one of the adults caught in 2015 (the one positive by microscopy) were positive by nested PCR (3/8, 37.5\%). In order to characterize these Plasmodium species, for those individuals $(N=3)$ that were positive by nested PCR, we obtained the parasite mtDNA genome sequences. We further examined these sequences by using phylogenetic analyses (Fig. 2) yielding two estimated gene trees, one just with partial $c y t b$ sequences commonly used to identify haemosporidia parasites (Bensch et al., 2009; Pacheco et al., 2018) and the other with mtDNA genome (Pacheco et al., 2018). These phylogenies have similar topologies. We found two lineages of Plasmodium (identified as 1 and 2 in Fig. 2) in three individuals of Hoatzin. The individuals caught in 2010 
206 (one adult and one juvenile) were infected with the same Plasmodium lineage (KY653750-

207 KY653751), and their mtDNA genome sequences were 100\% identical.

208

209 DISCUSSION

210 This is the first report of Plasmodium species in this bird and the first record of microfilarias in

211 Hoatzins from Venezuela. We have no sign of pathogenesis associated with these infections.

212 However, as numbers of heterophils and lymphocytes could be affected by stress such as a parasitic

213 infection, the ratio of one to the other $(\mathrm{H}: \mathrm{L})$ is commonly used as a stress indicator (Gross \& Siegel,

214 1983; Maxwell, 1993). Thus, we reported the H:L ratio since it is expected to increase in response

215 to stressors such as infectious diseases (Davis et al., 2008), especially in birds with high

216 parasitemia (Granthon \& Williams, 2017). Here, the bird infected with filarial parasites and

217 Plasmodium sp. had an increase in the number of lymphocytes and a decrease in the number of

218 heterophils in comparation with the haemosporidian negative birds (infected only with microfilaria

219 and uninfected individuals), and so a lower H:L ratio (1.5 vs. 2.4, Table 2). The opposite occurred

220 in the individual infected only with filarial parasites $(\mathrm{H}: \mathrm{L}=3.9$ vs. 2.4 , Table 2$)$. WBC counts are

221 difficult to interpret within and between species (e.g., Ricklefs \& Sheldon, 2007) so these results

222 should be taken with caution especially considering that these are a few individuals from a small

223 sample. Considering the paucity of data from this species, we provided the WBC count measures

224 for comparison in future studies. Although it has been hypothesized an association between

225 erythrocyte size and the species body size as result of differences in their metabolic rates (Hartman

$226 \&$ Lessler, 1963), we found that erythrocyte size from Hoatzins was comparable to those reported

227 from putative sister taxa like Gruiiformes (Jarvis et al., 2014; Claramunt \& Cracraft, 2015),

228 Charadriiformes (Claramunt \& Cracraft, 2015), and Accipitriformes (Prum et al., 2015) (Table 1). 
229 Furthermore, differential white blood cell (WBC) count profiles (Table 2) from non-infected

230 individuals showed marked similitude with those reported in nonpasserine birds such as cranes,

231 raptors, and vultures (Davis, 2009).

232 Wherever there are subpatent infections, it is difficult to determine the prevalence of 233 haemosporidian parasites since those infections are usually submicroscopic. In such cases, 234 parasites can only be detected by polymerase chain reaction using genes with high copy number 235 like cytb (Pacheco et al., 2018). The molecular diagnostic detected two lineages of Plasmodium 236 genus (Fig. 2) in these three individuals of Hoatzin. Interesting, the lineage found in the individuals 237 caught in 2010 (one adult and one juvenile) has been only reported so far in Brazil (Villar et al., 238 2013; Ferreira et al., 2017; Tostes et al., 2017) suggesting that it is distributed solely in South 239 America. In particular, its partial cytb sequence match $100 \%$ with a parasite lineage reported in several bird species: MYCAME02 isolated from Wood Storks nestlings found in the northern region of Brazil (Mycteria Americana, Pelecaniformes)(Villar et al., 2013), H2 isolate from

242 Streaked Flycatcher found in Southeastern Brazil (Myiodynastes maculatus,

243 Passeriformes)(Ferreira et al., 2017), and lineages reported from birds belonging to the orders 244 Strigiformes, Accipitriformes, and Falconiformes kept in captivity in Southeaster Brazil (Tostes 245 et al., 2017). In the phylogenetic analysis, this lineage appears as the sister taxon of Plasmodium 246 nucleophilum, parasite isolated from an Egyptian Goose in São Paulo Zoo, Brazil (Chagas et al., 247 2013). Both parasites, the lineage reported here and P. nucleophilum, are part of a monophyletic 248 group that includes Plasmodium ashfordi and Plasmodium delichoni. This monophyletic group is 249 at the base of the mitochondrial phylogeny of the known Avian Plasmodium parasites. Given the 250 lack of gametocyte data, it is possible that the Plasmodium infections in these two Hoatzin 251 individuals were abortive, but the fact that the two individuals (caught together) were infected with 
252 the same parasite suggests that its transmission is occurring, and the parasite lineage is circulating

253 in Cojedes State, Venezuela. Tostes et al., (2017) re-described the parasite linked to this cytb

254 lineage as Plasmodium (Novyella) paranucloephilum, a species originally described by Manwell

$255 \&$ Sessler (1971) in a South American tanager of uncertain species likely from northern Brazil.

256 However, given the absence of morphological data in this study, and that there is no $c y t b$ neither

257 other mtDNA genome sequences belonging to the original parasite description, we consider that it

258 is premature to identify the lineage found in this study as $P$. paranucloephilum. The identity of

259 this lineage could be established when more samples from birds with high parasitemia of this

260 haemosporidian parasite become available.

261 Regarding the second lineage found infecting hoatzin (KY653749, Fig. 2), it appears as the

262 common ancestor of a clade that includes Plasmodium tejerai, Plasmodium matutinum and

263 Plasmodium lutzi. This clade forms a monophyletic group with P. elongatum (Fig. 2); one of the

264 most pathogenic and generalist avian malaria parasite worldwide (Palinauskas et al., 2016). Given

265 that we did not find any sequence with $100 \%$ similarity with our lineage in the available databases,

266 this result indicates that likely a new parasite is circulating in the area. Considering the difficulty

267 of catching this bird species, it is worth noticing that even with this small sample size (only eight

268 individuals including four nestlings) we found two Plasmodium lineages infecting the Hoatzins.

269 Riparian zones from the Orinoco and Amazon basins are considered important in terms of their

270 biodiversity since they result from variable flood regimes, geographically unique channel

271 processes, altitudinal climate shifts, and upland influences on fluvial corridors. Furthermore, these

272 areas are treated as critical habitat to several endangered bird species, refuges to the fauna

273 inhabiting adjacent areas and, in some cases, hotspots and corridors for bird migration and

274 dispersal (Naiman \& Decamps, 1997; Franchin et al., 2009). In the Amazonia, the ability of avian 
275 malaria parasites to disperse geographically and shift among avian hosts have been played a role

276 in their radiation and have shaped their current distributions and diversity (Sebaio et al., 2012;

277 Fecchio et al. 2018a; 2018b). Thus, the fact that one of the lineages reported in the Hoatzin has

278 been found also in species in Brazil is consistent with this notion of broad geographic distribution

279 and multiple hosts. This finding also indicate that the parasite communities in the Orinoquia and

280 the Amazon basin share species so, at this point, we can only speculate that similar processes may

281 shape the parasite communities in both areas.

282 Riparian ecosystems in the Orinoquia are in a state of dynamic flux due to human interventions,

283 seasonal flooding, and fires. In addition, these areas are suitable for insects that could act as

284 vectors. Considering all these factors, the Orinoquia should be given special priority for future

285 research in order to document its parasite-avian host ecology and biodiversity.

286

287 ACKNOWLEDGEMENTS

288 The authors express their sincere gratitude to the local personnel at the study sites that helped with 289 trapping the birds. We thank Ariana Cristina Pacheco for the silhouettes design and the DNA 290 laboratory at the School of Life Sciences (Arizona State University) for their technical support.

291

292 LITERATURE CITED

293 Atkinson, CT, Samuel MD. 2010. Avian malaria Plasmodium relictum in native Hawaiian forest Avian Biology 41: 357-366. 
296

297

298

299

300

301

302

303

304

305

306

307

308

309

310

311

312

313

314

315

316

317

Altschul SF, Madden TL, Schäffer AA, Zhang J, Zhang Z, Miller W, Lipman DJ. 1997. Gapped BLAST and PSI-BLAST: a new generation of protein database search programs. Nucleic Acids Research 125:3389-3402.

Bardele CF, Schultheiß S, Lynn DH, Wright AG, Dominguez-Bello MG, Obispo NE. 2017. Aviisotricha hoazini n. gen., n. sp., the morphology and molecular phylogeny of an anaerobic ciliate from the crop of the Hoatzin (Opisthocomus hoazin), the cow Among the Birds. Protist 168:335-351.

Bauchan GR, Ochoa R, Hernandes FA, Bauchan GR. 2017. New and little known feather mites (Acariformes: Astigmata) analysed with low-temperature scanning electron microscopy. International Journal of Acarology 43:499-517.

Bensch S, Hellgren O, Pérez-Tris J. 2009. MalAvi: a public database of malaria parasites and related haemosporidians in avian hosts based on mitochondrial cytochrome b lineages. Molecular Ecology Resources 9:1353-1358.

Benson DA, Cavanaugh M, Clark K, Karsch-Mizrachi I, Lipman DJ, Ostell J, Sayers EW. 2012. GenBank. Nucleic Acids Research 41:D36-42.

Cavalier-Smith T. 2014. Gregarine site-heterogeneous 18S rDNA trees, revision of gregarine higher classification, and the evolutionary diversification of Sporozoa. European Journal of Protistology 50:472-495.

Chagas CR, Valkiūnas G, Nery CV, Henrique PC, Gonzalez IH, Monteiro EF, Guimarães Lde O, Romano CM, Kirchgatter K. 2013. Plasmodium (Novyella) nucleophilum from an Egyptian Goose in São Paulo Zoo, Brazil: microscopic confirmation and molecular characterization. International Journal for Parasitology: Parasites and Wildlife 2:286-291. 
318 Claramunt S, Cracraft J. 2015. A new time tree reveals Earth history's imprint on the evolution

319 of modern birds. Science Advances 1:e1501005.

320 Clark P, Boardman W, Raidal SR. 2009. Atlas of clinical avian hematology. Wiley-Blackwell, 321 Oxford.

Davis, AK. 2009. The Wildlife Leukocytes Webpage: The ecologist's source for information about leukocytes of wildlife species. http://wildlifehematology.uga.edu.

Davis AK, Maney DL, Maerz JC. 2008. The use of leukocyte profiles to measure stress in vertebrates: a review for ecologists. Functional Ecology 22:760-772.

Fecchio A, Bell JA, Collins MD, Farias IP, Trisos CH, Tobias JA, Tkach VV, Weckstein JD,

Fecchio A, Pinheiro R, Felix G, Faria IP, Pinho JB, Lacorte GA, Braga EM, Farias IP, Aleixo Ricklefs RE, Batalha-Filho H. 2018a. Diversification by host switching and dispersal shaped the diversity and distribution of avian malaria parasites in Amazonia. Oikos 127:1233-1242.

A, Tkach VV, Collins MD, Bell JA, Weckstein JD. 2018b. Host community similarity and geography shape the diversity and distribution of haemosporidian parasites in Amazonian birds. Ecography 41:505-515.

Ferreira Junior FC, Rodrigues RA, Ellis VA, Leite LO, Borges MAZ, Braga ÉM. 2017. Habitat modification and seasonality influence avian haemosporidian parasite distributions in southeastern Brazil. PLoS One 12(6): 0178791.

Franchin, R de F., Kanegae MF, Marçal OJr. 2009. Birds in the tropical savannas. In: K. Del Claro, P. S. Oliveira, V. Rico-Gray, Eds.Tropical Biology and Conservation Management Volume X: Savanna Ecosystems. Eolss Publishers Co. Ltd., Oxford, UK, 160-197.

Gabaldon A. 1998. Malaria aviaria en un país de la región neotropical Venezuela. Fundación Venezolana para la Salud, Caracas, Venezuela 
341 Garnham PCC. 1966. Malaria parasites and other Haemosporidia. Blackwell Scientific

342 Publications, Oxford, U.K.

343 Granthon C, Williams DA. 2017. Avian malaria, body condition, and blood parameters in four 344 species of songbirds. The Wilson Journal of Ornithology 129:492-508.

345 Godoy-Vitorino F, Goldfarb KC, Brodie EL, Garcia-Amado MA, Michelangeli F, 346 Domínguez-Bello MG. 2010. Developmental microbial ecology of the crop of the folivorous 347 hoatzin. The ISME Journal 4:611-620.

Godoy-Vitorino F, Leal SJ, Díaz WA, Rosales J, Goldfarb KC, García-Amado MA, 349 Michelangeli F, Brodie EL, Domínguez-Bello MG. 2012. Differences in crop bacterial

Gouy M, Guindon S, Gascuel O. 2010. SeaView version 4: a multiplatform graphical user interface for sequence alignment and phylogenetic tree building. Molecular Biology and Evolution 272:221-224.

Grajal A, Strahl SD, Parra R, Gloria Dominguez M, Neher A. 1989. Foregut fermentation in 356 the hoatzin, a neotropical leaf-eating bird. Science 245:1236-1238.

González-Fernández AJ, González-Fernández ME, Méndez G, Campo-Zambrano MA, El Baúl, Venezuela, 292 pp. 
363 Hernandes FA, Mironov SV. 2015. The feather mites of the hoatzin Opisthocomus hoazin

364 (Müller) (Aves: Opisthocomiformes), with the description of two new genera and six new 365 species (Acari: Analgoidea, Pterolichoidea). Zootaxa 4034:401-44.

366 Jarvis ED, Mirarab S, Aberer AJ, Li B, Houde P, Li C, Ho SY, Faircloth BC, Nabholz B, 367 Howard JT, Suh A, Weber CC, da Fonseca RR, Li J, Zhang F, Li H, Zhou L, Narula N, 368 Liu L, Ganapathy G, Boussau B, Bayzid MS, Zavidovych V, Subramanian S, Gabaldón 369 
386

387

388

389

390

391

392

393

394

395

396

397

398

399

400

401

402

403

404

405

406

407

408

Maxwell M. 1993. Avian blood leucocyte responses to stress. World's Poultry Science Journal 49: 34-43.

McKeand JB. 1998. Molecular diagnosis of parasitic nematodes. Parasitology 117:S87-S96.

Muñoz E, Ferrer D, Molina R, Adlard RD. 1999. Prevalence of haematozoa in birds of prey in Catalonia, north-east Spain. Veterinary Record 144:632-636.

Naiman RJ, Decamps H. 1997. The ecology of interfaces: Riparian zones. Annual Review of Ecology, Evolution, and Systematics 28:621-58.

Pacheco MA, Battistuzzi FU, Junge RE, Cornejo OE, Williams CV, Landau I, Rabetafika L, Snounou G, Jones-Engel L, Escalante AA. 2011. Timing the origin of human malarias: the lemur puzzle. BMC Evolutionary Biology 11:299.

Pacheco MA, Cepeda AS, Bernotienè R, Lotta IA, Matta NE, Valkiūnas G, Escalante AA. 2018. Primers targeting mitochondrial genes of avian haemosporidians: PCR detection and differential DNA amplification of parasites belonging to different genera. International Journal for Parasitology 48:657-670.

Palinauskas V, Žiegytė R, Iezhova TA, Ilgūnas M, Bernotienė R, Valkiūnas G. 2016. Description, molecular characterisation, diagnostics and life cycle of Plasmodium elongatum (lineage pERIRUB01), the virulent avian malaria parasite. International Journal for Parasitology 46:697-707.

Prum RO, Berv JS, Dornburg A, Field DJ, Townsend JP, Lemmon EM, Lemmon AR. 2015. A comprehensive phylogeny of birds (Aves) using targeted next-generation DNA sequencing. Nature 526:569-573.

Renjifo S, CJ Sanmartin y JA De Zuleta. 1952. A survey of the blood parasites of vertebrates in eastern Colombia. Acta Tropica 9:121-169. 
409

410

411

412

413

414

415

416

417

418

419

420

421

422

423

424

425

426

427

428

429

430

Ricklefs RE, Sheldon KS. 2007. Malaria prevalence and white-blood-cell response to infection in a tropical and in a temperate thrush. Auk 124:1254-1266

Ronquist F, Huelsenbeck JP. 2003. MrBayes 3: Bayesian phylogenetic inference under mixed models. Bioinformatics 1912:1572-1574.

Schneider CA, Rasband WS, Eliceiri KW. 2012. NIH Image to ImageJ: 25 years of image analysis. Nature Methods 9:671-675.

Sebaio F, Braga EM, Branquinho F, Fecchio A, Marini MÂ. 2012. Blood parasites in passerine birds from the Brazilian Atlantic Forest. The Revista Brasileira de Parasitologia Veterinária 21:7-15.

Telford SR Jr. 2009. Hemoparasites of the Reptilia: color atlas and text. Taylor \& Francis, Boca Raton.

Thomas BT. 1996. Family Opisthocomidae (Hoatzin). In: J. del Hoyo, A. Elliott, and J. Sargatal, Eds. Handbook of the Birds of the World, vol. 3: Hoatzin to Auks. Lynx Edicions, Barcelona, Spain, 24-32.

Tostes R, Dias RJP, Martinele I, Senra MVX, D'Agosto M, Massard CL. 2017. Multidisciplinary re-description of Plasmodium (Novyella) paranucleophilum in Brazilian wild birds of the Atlantic Forest kept in captivity. Parasitology Research 116:1887-1897.

Valkiūnas G. 2005. Avian malaria parasites and other haemosporidia. CRC press

Valkiūnas G, Iezhova TA. 2018. Keys to the avian malaria parasites. Malaria Journal 17(1):212.

Villar CM, Bryan AL Jr, Lance SL, Braga EM, Congrains C, Del Lama SN. 2013. Blood parasites in nestlings of wood stork populations from three regions of the American continent. Journal of Parasitology 99:522-527. 
431 Viscarret P, Wright J, Urbani F. 2009. New U-Pb zircon ages of El Baul Massif, Cojedes State, 432 Venezuela. Revista Tecnica de la Facultad de Ingenieria Universidad del Zulia 32:210-221. 


\section{Table $\mathbf{1}$ (on next page)}

Comparison of erythrocyte measurements from different bird orders including the values for Hoatzin.

The values for Hoatzin (O. hoazin) are from six individuals caught in August 2015 at the

Cojedes River, Venezuela.*Erythrocyte measurements are from Hartman and Lessler (1963) and \&from Tostes et al. (2017). 


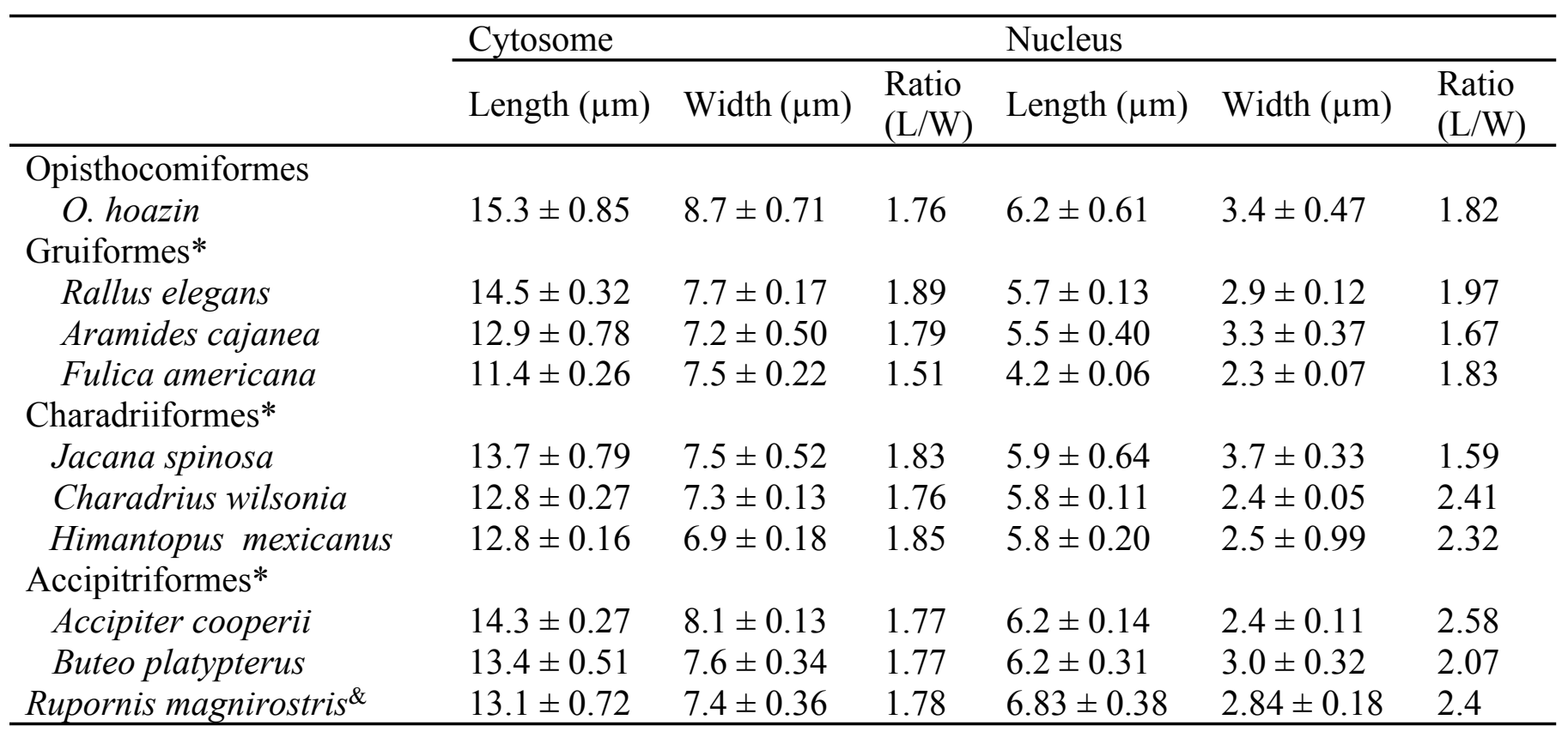

2

3

4

5

6

7

8

9

10 
Table 2 (on next page)

Differential white blood cell $(\mathrm{WBC})$ counts and $\mathrm{H}: \mathrm{L}$ ratio in the Hoatzins $(N=6)$ caught in August 2015 at the Cojedes River, Venezuela. 
1

\begin{tabular}{llll}
\hline & $\begin{array}{l}\text { Uninfected } \\
\text { nestlings }\end{array}$ & Infected adults \\
\cline { 2 - 4 } & $(N=4)$ & $\begin{array}{l}\text { microfilaria } \\
(N=1)\end{array}$ & $\begin{array}{l}\text { microfilaria/Plasmodium } \\
(N=1)\end{array}$ \\
\hline Heterophils & $64.25 \pm 2.75$ & 67 & 53 \\
Lymphocytes & $27 \pm 1.83$ & 17 & 35 \\
Monocytes & $5 \pm 0.82$ & 8 & 5 \\
Eosinophils & $3.25 \pm 0.5$ & 7 & 5 \\
Basophils & $0.5 \pm 0.58$ & 1 & 1 \\
H:L & 2.4 & 3.9 & 1.5 \\
\hline
\end{tabular}

2

3

4 
Figure 1

Microfilaria and Plasmodium sp. blood stage infecting the Hoatzins (O. hoazin) caught in August 2015 at the Cojedes River, Venezuela.

(A) Hoatzin individual infected only with filarial parasites. $\left(B^{*}\right),\left(C^{*}\right)$, and $\left(D^{\S}\right)$ Hoatzin individual infected with filarial parasites and Plasmodium sp. *Microfilarial stages of the filarial parasite (Scale bar $=20 \mu \mathrm{m}$ ) and ${ }^{\star}$ Plasmodium sp. trophozoite (Scale bar $=10 \mu \mathrm{m}$ ). We indicated the hemoparasite stages by the black arrows. 


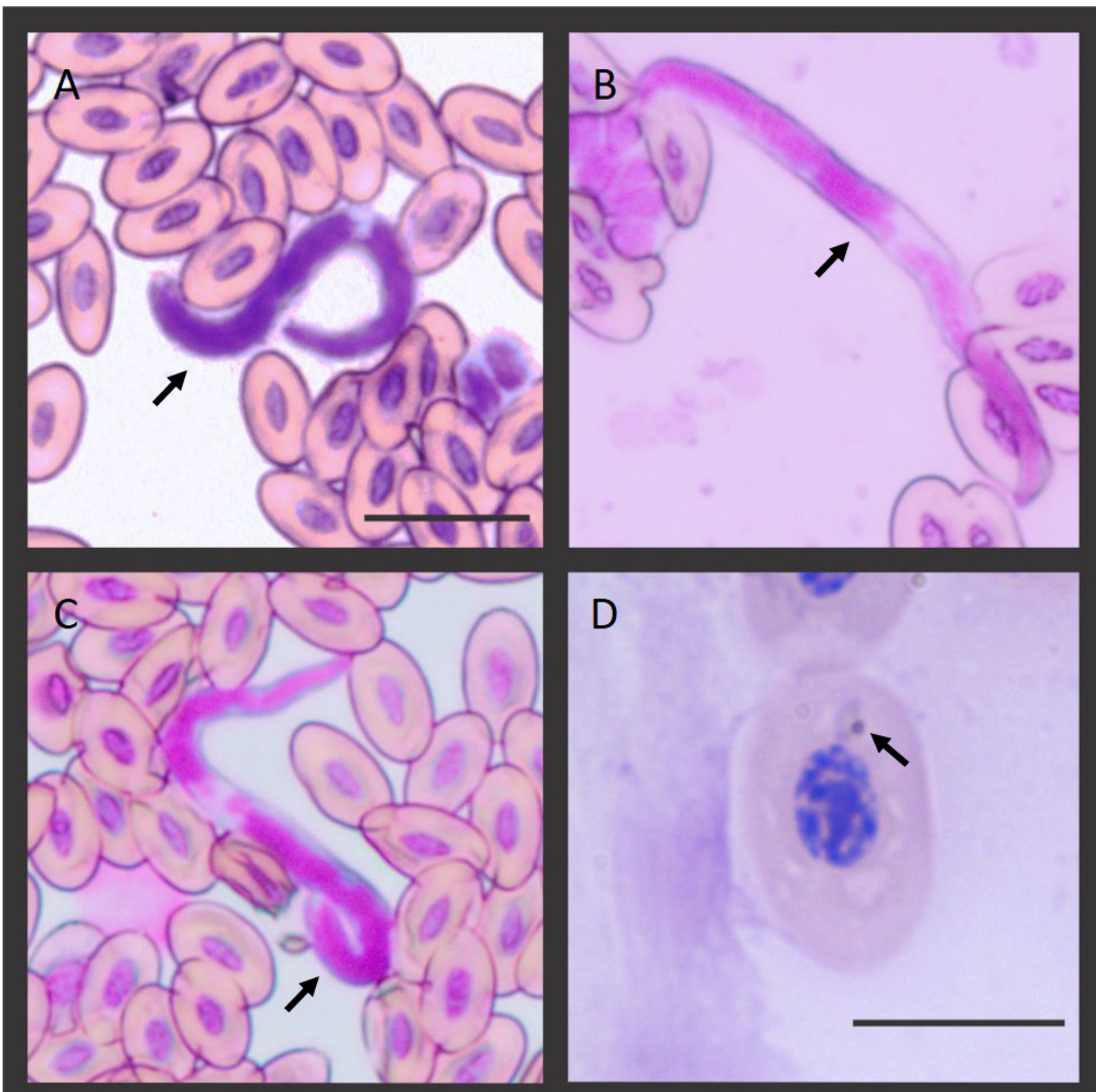




\section{Figure 2 (on next page)}

A Bayesian phylogenetic hypothesis of Plasmodium parasites infecting the Hoatzins ( $O$. hoazin) caught at the Cojedes River, Venezuela.

We constructed phylogenetic trees based on parasites $(A)$ partial sequences of the cytb gene (45 sequences and 480 bp excluding gaps) and mtDNA genomes (31 sequences and 5286 bp excluding gaps). The values above branches are posterior probabilities (see "Material and methods"). Leucocytozoon genus (outgroup) is indicated in grey. We provided in parentheses both lineages (as deposited in the MalAvi database) and their Genbank accession numbers for all the sequences used in the analyses. 


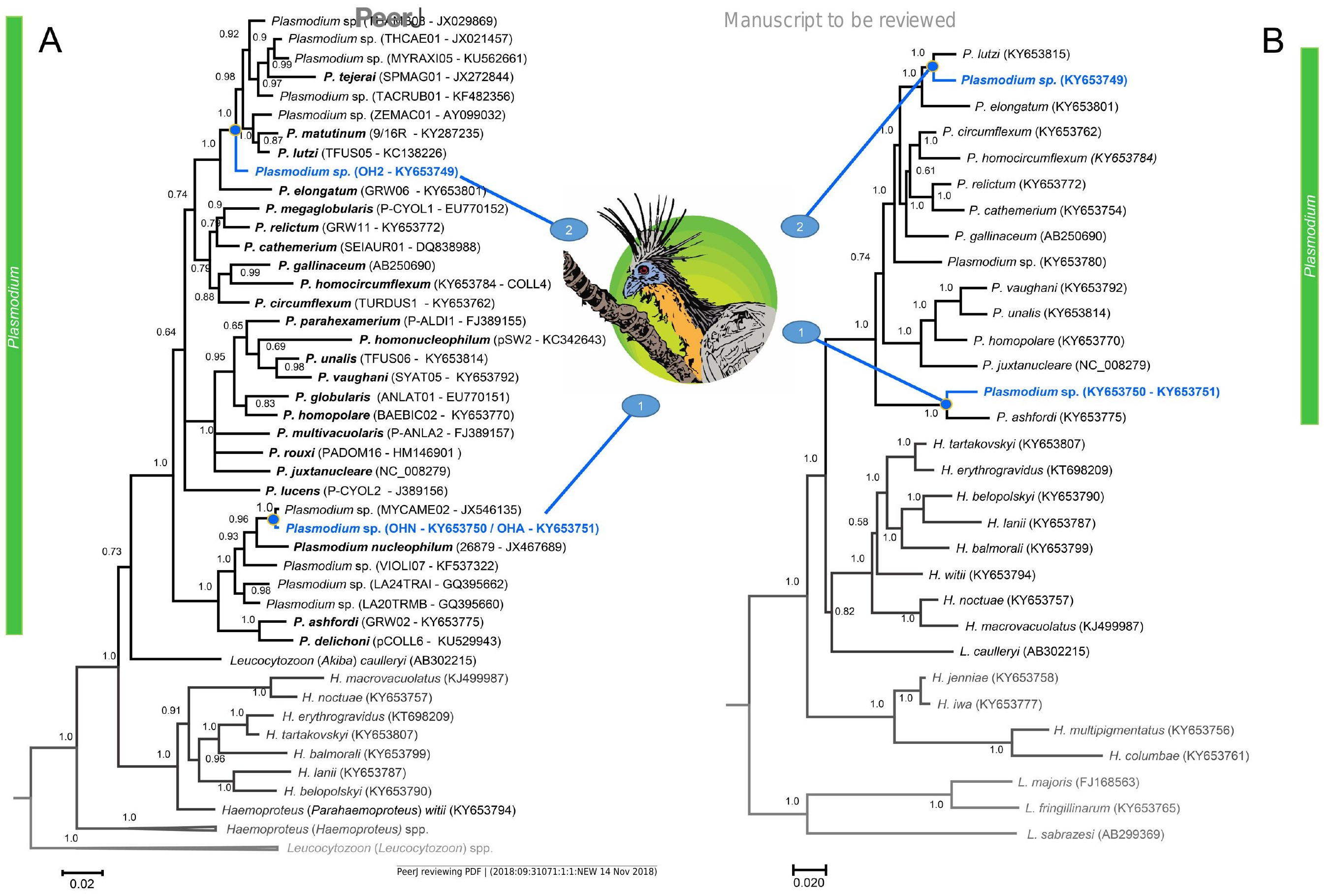

